\title{
Metal Cutting Tool Position Control using Static Output Feedback and Full State Feedback $\mathrm{H}_{2}$ Controllers
}

\author{
Mustefa Jibril ${ }^{1}$, Messay Tadese ${ }^{2}$, Roman Jirma ${ }^{3}$ \\ ${ }^{1}$ Msc, School of Electrical \& Computer Engineering, Dire Dawa Institute of Technology, Dire Dawa, \\ Ethiopia \\ ${ }^{2}$ Msc, School of Electrical \& Computer Engineering, Dire Dawa Institute of Technology, Dire Dawa, \\ Ethiopia \\ ${ }^{3}$ Msc, School of Industrial\& Mechanical Engineering, Dire Dawa Institute of Technology, Dire Dawa, \\ Ethiopia \\ mustefa.jibril@ddu.edu.et
}

\begin{abstract}
In this paper, a metal cutting machine position control have been designed and simulated using Matlab/Simulink Toolbox successfully. The open loop response of the system analysis shows that the system needs performance improvement. Static output feedback and full state feedback H 2 controllers have been used to increase the performance of the system. Comparison of the metal cutting machine position using static output feedback and full state feedback $\mathrm{H} 2$ controllers have been done to track a set point position using step and sine wave input signals and a promising results have been analyzed.
\end{abstract}

Keywords: Metal cutting machine, Static output feedback, Full state feedback H 2 controllers

\section{Introduction}

A metal cutting machine or cutter tool is any tool that is used to separate some metallic material from the work piece by means of cutting. Cutting may be accomplished by single-point or multipoint tools. Single point tools are used in turning, shaping, planing and similar operations, and remove material by means of one cutting edge. Cutting tool materials must be harder than the material which is to be cut, and the tool blade must be in accurate position. The Coordinate position of the blade might be 1D (dimension), 2D and 3D and it must be able to withstand the disturbances that arise for example from the force generated in the metal-cutting process. Also, the tool must have a specific geometry, with clearance angles designed so that the cutting edge can contact the work piece without the rest of the tool dragging on the work piece surface.

\section{Mathematical Modeling}

A solenoid system is fed with an electrical voltage. The force exerted by the solenoid system is proportional to the current. This force controls the hydraulic actuator input. The hydraulic actuator system is fed with fluid from a constant pressure source in which the compressibility of the fluid is negligible. An input displacement x moves the control valve; thus fluid passes in to the upper part of the cylinder and the piston is forced to move horizontally. A low power displacement of $\mathrm{x}(\mathrm{t})$ causes a large high power displacement $\mathrm{y}(\mathrm{t})$. The output displacement moves the cutter blade. The system layout is shown in Figure 1 below. 


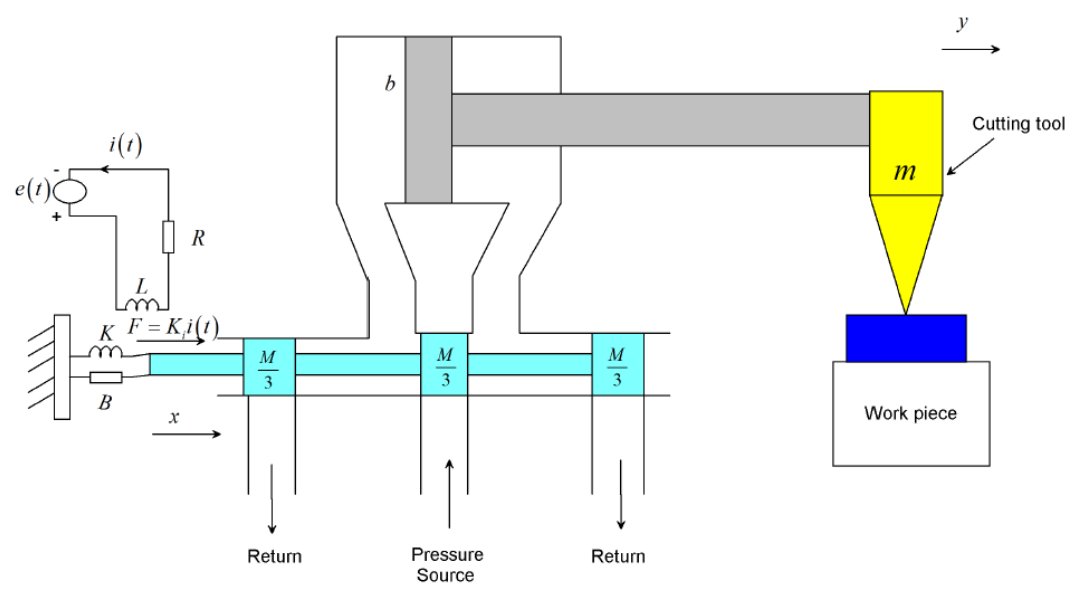

Figure 1 Metal Cutter Machine

The solenoid coil circuit equation becomes

$$
e(t)=\operatorname{Ri}(t)+L \frac{d i(t)}{d t}
$$

Taking Laplace transform and arranging the transfer function between the input voltage and the output current become

$$
\frac{I(s)}{E(s)}=\frac{1}{L s+R}
$$

The force on the shaft is proportional to the current $\mathrm{i}(\mathrm{t})$ so that

$$
F=K_{i} i(t)
$$

Taking Laplace transform and arranging the transfer function between the input current and the output force become

$$
\frac{F(s)}{I(s)}=K_{i} s
$$

The force balance equation of the control valve becomes

$$
M \frac{d^{2} x}{d t^{2}}+B \frac{d x}{d t}+K x=F
$$

Taking Laplace transform and arranging the transfer function between the input force and the output displacement become

$$
\frac{X(s)}{F(s)}=\frac{1}{M s^{2}+B s+K}
$$


The flow rate of the fluid $\mathrm{Q}$ is related to the input displacement $\mathrm{x}(\mathrm{t})$ and the differential pressure across the piston will be

$$
Q=g(x, P)
$$

Using Taylor series linearization technique we have

$$
Q=\left(\frac{\partial g}{\partial x}\right)_{x_{0}, p_{0}} x+\left(\frac{\partial g}{\partial P}\right)_{x_{0}, p_{0}} P=k_{x} x+k_{p} P
$$

Where $g=g(x, P)$ and $\left(x_{0}, p_{0}\right)$ is the operating point, the piston developed a force which is the area of the piston A multiplied by the pressure $\mathrm{P}$.

The applied force to the mass become

$$
A P=m \frac{d^{2} y}{d t^{2}}+b \frac{d y}{d t}
$$

Where

m mass of the cutter

b Damping coefficient of the piston

Substituting Equation (8) in to Equation (9) yields:

$$
\frac{A}{k_{p}}\left(k_{x} x-Q\right)=m \frac{d^{2} y}{d t^{2}}+b \frac{d y}{d t}
$$

The fluid flow is proportional to the to the piston movement as

$$
Q=K_{q} y
$$

Substituting Equation (11) in to Equation (10) and rearranging yields:

$$
\frac{A k_{x}}{k_{p}} x=m \frac{d^{2} y}{d t^{2}}+b \frac{d y}{d t}+\frac{A K_{q}}{k_{p}} y
$$

Therefore the transfer function between the output displacement and input displacement will be:

$$
\frac{Y(s)}{X(s)}=\frac{\left(\frac{A k_{x}}{k_{p}}\right)}{\left(m s^{2}+b s+\frac{A K_{q}}{k_{p}}\right)}
$$

Therefore, the overall transfer function between the input voltage and the output cutter blade position can be obtaining by multiplying Equation (2), (4), (6) and (13). 


$$
G(s)=\frac{Y(s)}{E(s)}=\frac{K_{i} K_{1}}{(L s+R)\left(M s^{2}+B s+K\right)\left(m s^{2}+b s+K_{2}\right)}
$$

Where

$$
\begin{aligned}
K_{1} & =\left(\frac{A k_{x}}{k_{p}}\right) \\
K_{2} & =\left(\frac{A K_{q}}{k_{p}}\right)
\end{aligned}
$$

The metal cutting machine parameters is shown in Table 1 below

Table 1 Metal cutting machine parameters

\begin{tabular}{|l|l|l|l|}
\hline No & Parameters & Symbol & Value \\
\hline 1 & Resistance & $R$ & $100 \mathrm{ohm}$ \\
\hline 2 & Inductance & $L$ & $13 \mathrm{H}$ \\
\hline 3 & $\begin{array}{l}\text { Spring stiffness attached to control } \\
\text { valve }\end{array}$ & $K$ & $12 \mathrm{~N} / \mathrm{m}$ \\
\hline 4 & $\begin{array}{l}\text { Damping coefficient attached to } \\
\text { control valve }\end{array}$ & $B$ & $3.3 \mathrm{~N}-\mathrm{s} / \mathrm{m}$ \\
\hline 5 & Mass of the control valve & $M$ & $1.4 \mathrm{Kg}$ \\
\hline 6 & Force current constant & $K_{i}$ & $18 \mathrm{~N} / \mathrm{A}$ \\
\hline 7 & Fluid piston constant & $K_{q}$ & 0.25 \\
\hline 1 & Mass of the cutter blade & $\mathrm{m}$ & $3 \mathrm{~kg}$ \\
\hline 2 & Area of the piston & $\mathrm{A}$ & $0.25 \mathrm{~m} 2$ \\
\hline 3 & Damping coefficient of the piston & $\mathrm{b}$ & $6.3 \mathrm{~N}-\mathrm{s} / \mathrm{m}$ \\
\hline 4 & Displacement constant & $k_{x}$ & 8 \\
\hline 5 & Pressure constant & $k_{p}$ & 4 \\
\hline
\end{tabular}

The transfer function of the system then becomes

$$
G(s)=\frac{Y(s)}{E(s)}=\frac{9}{54.6 s^{5}+663.4 s^{4}+2725 s^{3}+7818 s^{2}+10630 s+7584}
$$

The state space representation of the system becomes 


$$
\begin{aligned}
& \dot{x}=\left(\begin{array}{ccccc}
-12.15 & -6.239 & -4.474 & -3.042 & -1.085 \\
8 & 0 & 0 & 0 & 0 \\
0 & 4 & 0 & 0 & 0 \\
0 & 0 & 2 & 0 & 0 \\
0 & 0 & 0 & 2 & 0
\end{array}\right) x+\left(\begin{array}{c}
0.03125 \\
0 \\
0 \\
0 \\
0
\end{array}\right) u \\
& y=\left(\begin{array}{lllll}
0 & 0 & 0 & 0 & 0.04121) x
\end{array}\right.
\end{aligned}
$$

\section{The Proposed Controllers Design}

\subsection{Static Output Feedback Controller Design}

Consider a linear time invariant system:

$$
\delta x(t)=A x(t)+B u(t) \quad y(t)=C x(t)
$$

Where

$$
\delta x(t)=\dot{x}(t)
$$

$x(t) \in R^{n}, u(t) \in R^{m}, y(t) \in R^{1}$ are state, control and output vectors, respectively; $\mathrm{A}, \mathrm{B}, \mathrm{C}$ are constant matrices of appropriate dimensions.

The feedback control law is considered in the form

$$
u(t)=F y(t)=F C x(t)=K x(t)
$$

where $\mathrm{F}$ is a static output feedback controller gain matrix. The closed-loop system is then

$$
\delta x(t)=A_{c} x(t)
$$

where

$$
A_{c}=A+B F C
$$

The block diagram of the cutter system with static output feedback controller gain matrix is shown in Figure 2 below.

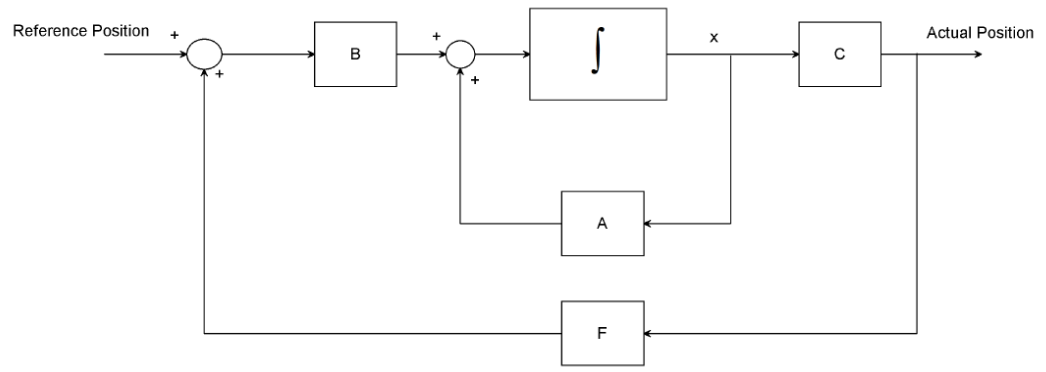

Figure 2 Block diagram of the cutter system with static output feedback controller gain matrix 
It is well known that the fixed order dynamic output feedback control design problem is a special case of the static output feedback problem, since the closed-loop system for the fixed order case has exactly the same structure as the static case with appropriately augmented system matrices [5]. Therefore, study of static output feedback problem includes more general scope of control problems. To assess the performance quality a quadratic cost function known from LQ theory is often used. However, in practice the response rate or overshoot are often limited. Therefore, we include into the LQR cost function the additional derivative term for state variable to open the possibility to damp the oscillations and limit the response rate.

$$
J_{c}=\int_{0}^{\infty}\left[x(t)^{T} Q x(t)+u(t)^{T} R u(t)+\delta x(t)^{T} S \delta x(t)\right] d t
$$

For this system the static output feedback controller gain matrix becomes

$$
F=[3.32]
$$

Then the feedback control law is becoming

$$
\begin{gathered}
u(t)=[3.32] y(t)=\left(\begin{array}{ccccc}
0 & 0 & 0 & 0 & 0.1368172
\end{array}\right) x(t) \\
K=\left(\begin{array}{lllll}
0 & 0 & 0 & 0 & 0.1368172
\end{array}\right)
\end{gathered}
$$

\subsection{Full State Feedback $H_{2}$ Controller Design}

Consider Figure 3 and assume that

$$
M=\left[\begin{array}{lll}
A & B_{1} & B_{2} \\
C_{1} & 0 & D_{12} \\
I & 0 & 0
\end{array}\right]
$$

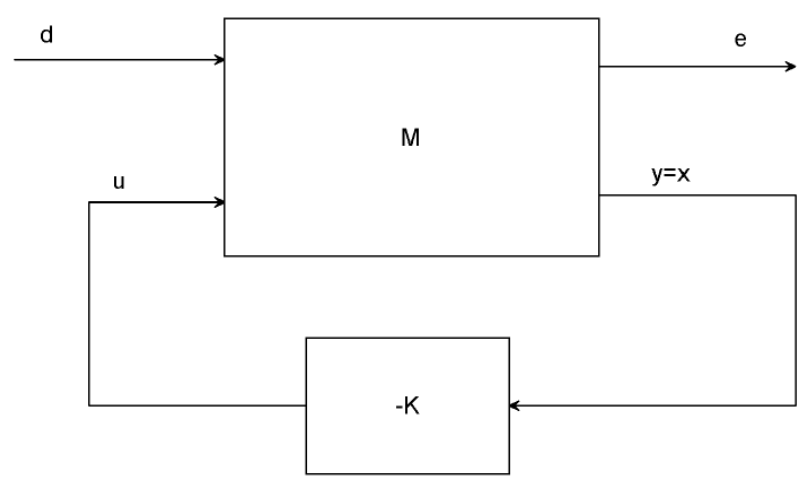

Figure 3 A full state feedback system.

From Equation (18),

$$
\dot{x}=A x+B_{1} d(t)+B_{2} u(t)
$$




$$
\begin{gathered}
e(t)=C_{1} x(t)+D_{12} u(t) \\
y(t)=x(t)
\end{gathered}
$$

Assuming that $d(t)$ is the white noise vector with unit intensity

$$
\left\|T_{e d}(s)\right\|_{H_{2}}^{2}=E\left(e^{T}(t) e(t)\right)
$$

Where

$$
e^{T} e=x^{T} C_{1}^{T} C_{1} x+2 x^{T} C_{1}^{T} D_{12} u+u^{T} D_{12}^{T} D_{12} u
$$

With Equation (19) and Equation (22), the minimization of $\left\|T_{e d}(s)\right\|_{H_{2}}$ is equivalent to the solution of the stochastic regulator problem. Setting

$$
Q_{f}=C_{1}^{T} C_{1}, \quad N_{f}=C_{1}^{T} D_{12} \text { and } R_{f}=D_{12}^{T} D_{12}
$$

the optimal state feedback law is given by

$$
u=-K x
$$

Where

$$
K=R_{f}^{-1}\left(P B_{2}+N_{f}\right)^{T}
$$

And

$$
P\left(A-B_{2} R_{f}^{-1} N_{f}^{T}\right)+\left(A-B_{2} R_{f}^{-1} N_{f}^{T}\right)^{T} P-P B_{2} R_{f}^{-1} B_{a}^{T} P+Q_{f}-N_{f} R_{f}^{-1} N_{f}^{T}=0
$$

It should be noted that the gain $K$ is independent of the matrix B1. For this system the full state feedback gain matrix becomes

$$
K=\left(\begin{array}{lllll}
-1.3453 & 0.2574 & 1.3754 & -0.3628 & 0.7077
\end{array}\right)
$$

\section{Result and Discussion}

Here in this section, the investigation of the open loop response and the closed loop response with the proposed controller for the comparison of the system have been done.

\subsection{Open Loop Response of the Cutter Machine}

The open loop response of the system for a 1400 volt input simulation is shown in Figure 4 below.

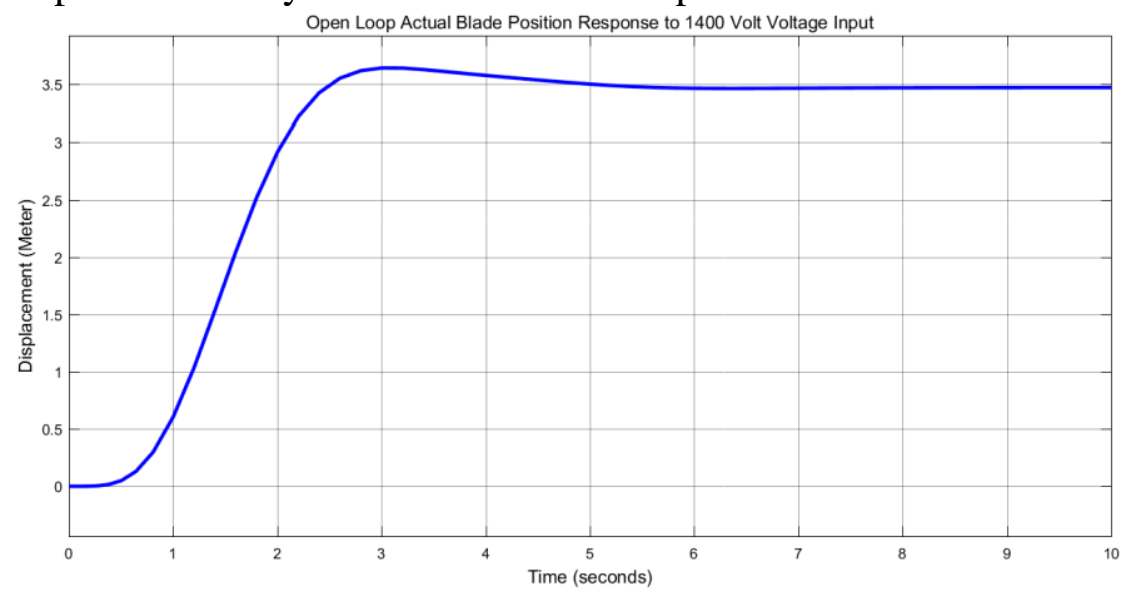


Figure 4 Open loop response

The open loop response of the machine shows that the system input is a high voltage and the system needs improvement.

\subsection{Comparison of the Cutting Machine using Static Output Feedback and Full State Feedback $\mathrm{H}_{2}$ Controllers using Step Input Desired Position Signal}

The Simulink model of the cutting machine using static output feedback and full state feedback $\mathrm{H}$ 2 controllers using step input desired position signal is shown in Figure 5 below.

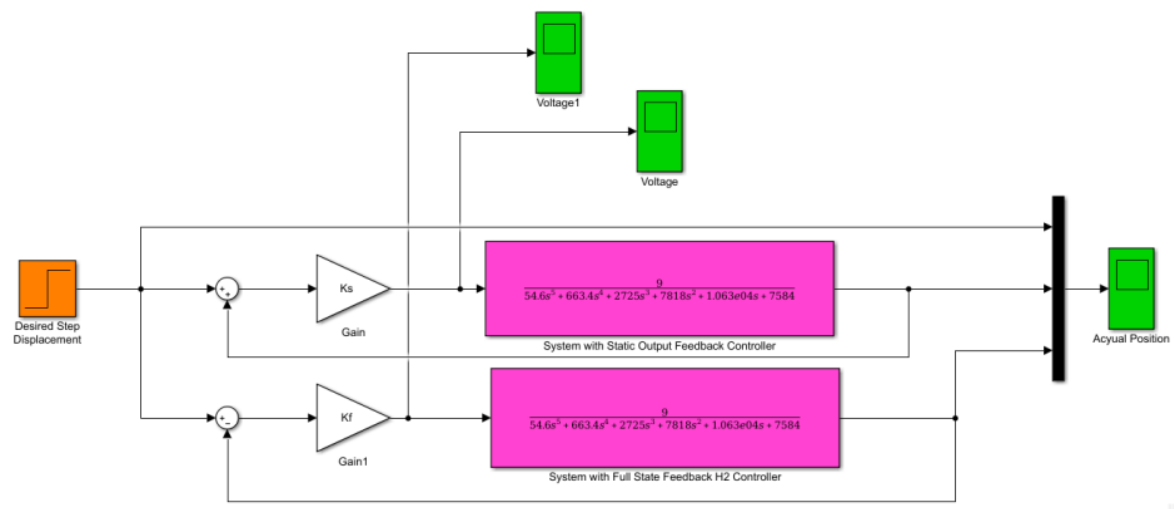

Figure 5 Simulink model of the cutting machine using static output feedback and full state feedback H 2 controllers using step input desired position signal

The simulation result of the comparison with the input voltage to the cutting machine using static output feedback and full state feedback H 2 controllers are shown in Figure 6, Figure 7 and Figure 8 respectively.

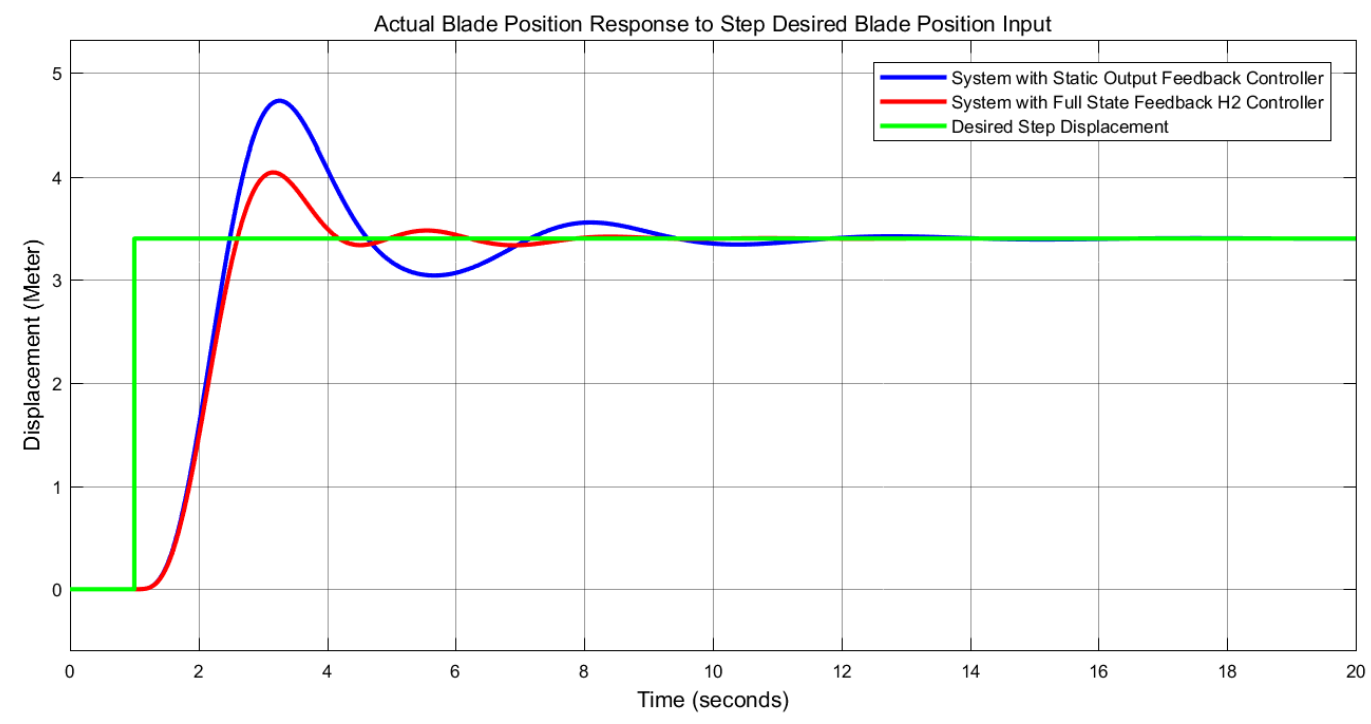

Figure 6 Step response of the comparison 


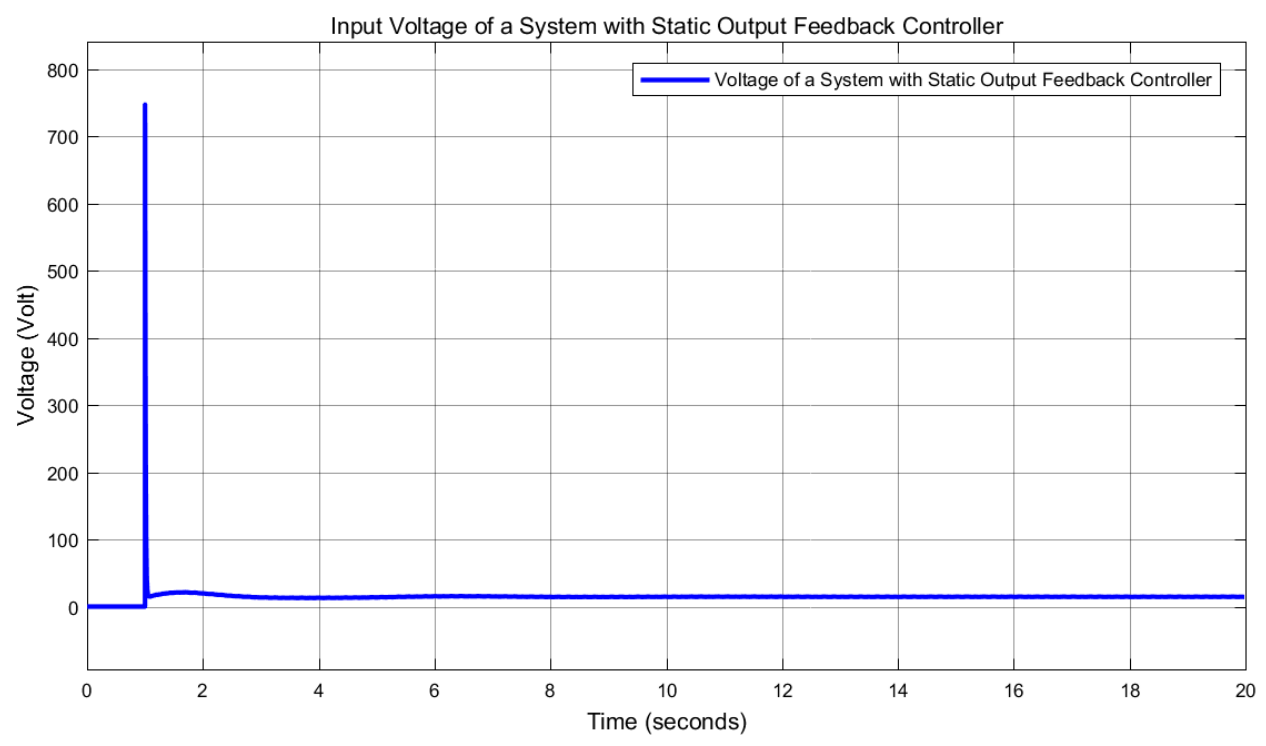

Figure 7 Input voltage to the system with static output feedback controller

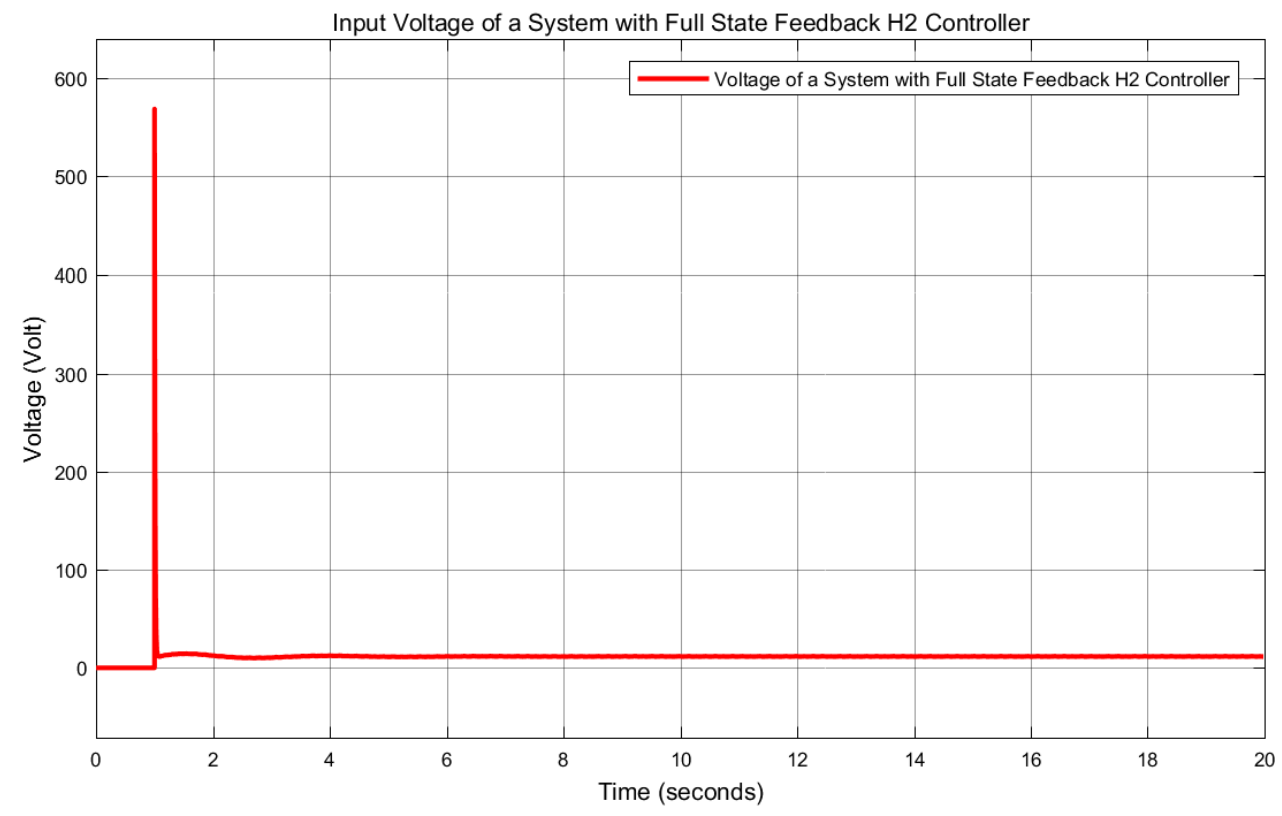

Figure 8 Input voltage to the system with full state feedback controller

The input voltages of the cutting machine system with the proposed controllers shows improvement in reducing the voltage amplitude but the system with full state feedback $\mathrm{H} 2$ controller shows better improvement. The data of the rise time, percentage overshoot, settling time and peak value is shown in Table 2.

Table 2 Step response data

\begin{tabular}{|l|l|l|l|}
\hline No & Performance Data & Full state feedback H2 controller & Static output feedback \\
\hline 1 & Rise time & $1.8 \mathrm{sec}$ & $1.8 \mathrm{sec}$ \\
\hline 2 & Per. overshoot & $17 \%$ & $34.2 \%$ \\
\hline
\end{tabular}




\begin{tabular}{|l|l|l|l|}
\hline 3 & Settling time & $8 \mathrm{sec}$ & $12 \mathrm{sec}$ \\
\hline 4 & Peak value & $4.1 \mathrm{~m}$ & $4.7 \mathrm{~m}$ \\
\hline
\end{tabular}

As Table 2 shows that the cutting machine system with full state feedback $\mathrm{H} 2$ controller improves the performance of the system by minimizing the percentage overshoot and settling time.

\subsection{Comparison of the Cutting Machine using Static Output Feedback and Full State Feedback $\mathrm{H}_{2}$ Controllers using Sine Wave Input Desired Position Signal}

The Simulink model of the cutting machine using static output feedback and full state feedback $\mathrm{H}$ 2 controllers using sine wave input desired position signal is shown in Figure 9 below.

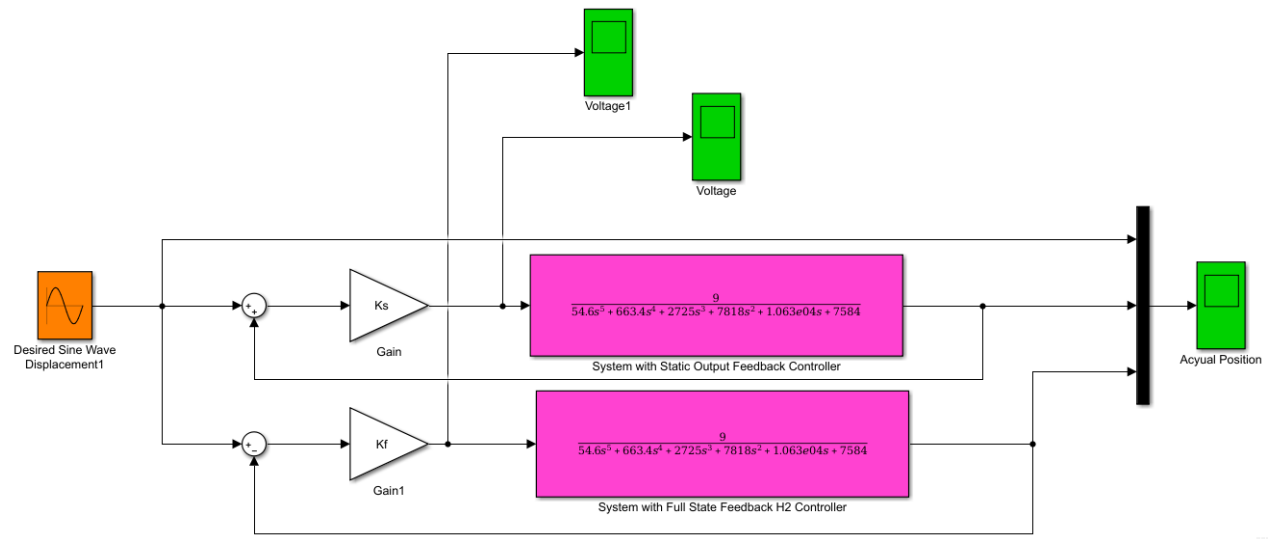

Figure 9 Simulink model of the cutting machine using static output feedback and full state feedback H 2 controllers using sine wave input desired position signal

The simulation result of the comparison with the input voltage to the cutting machine using static output feedback and full state feedback H 2 controllers are shown in Figure 10, Figure 11 and Figure 12 respectively.

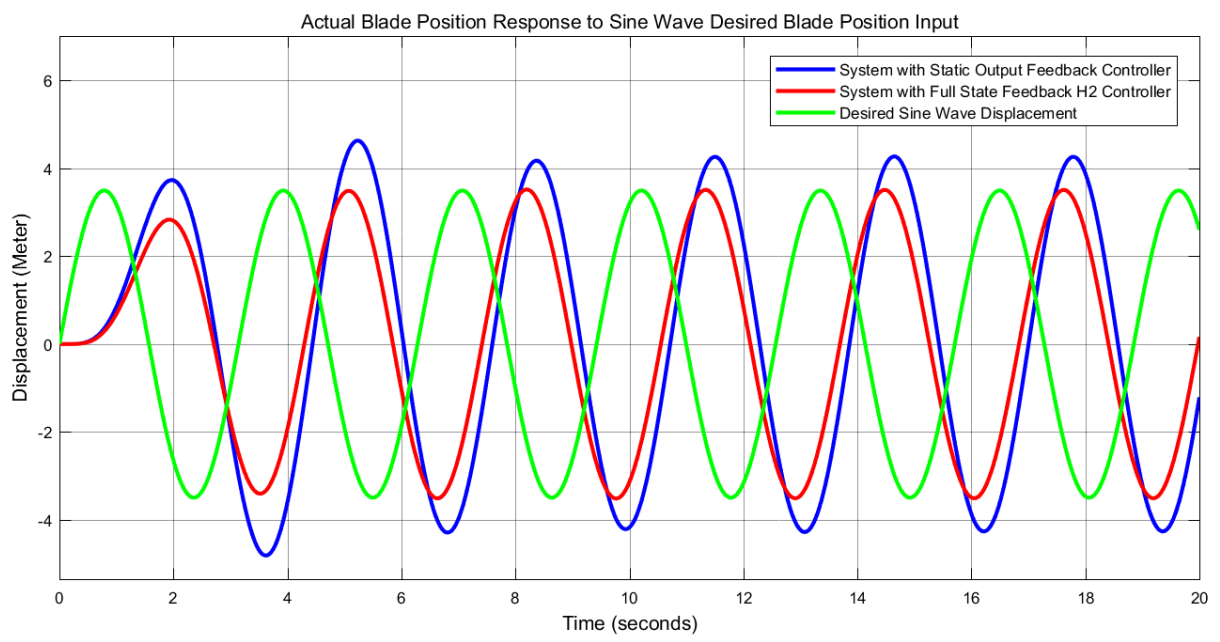

Figure 10 Sine wave response of the comparison 


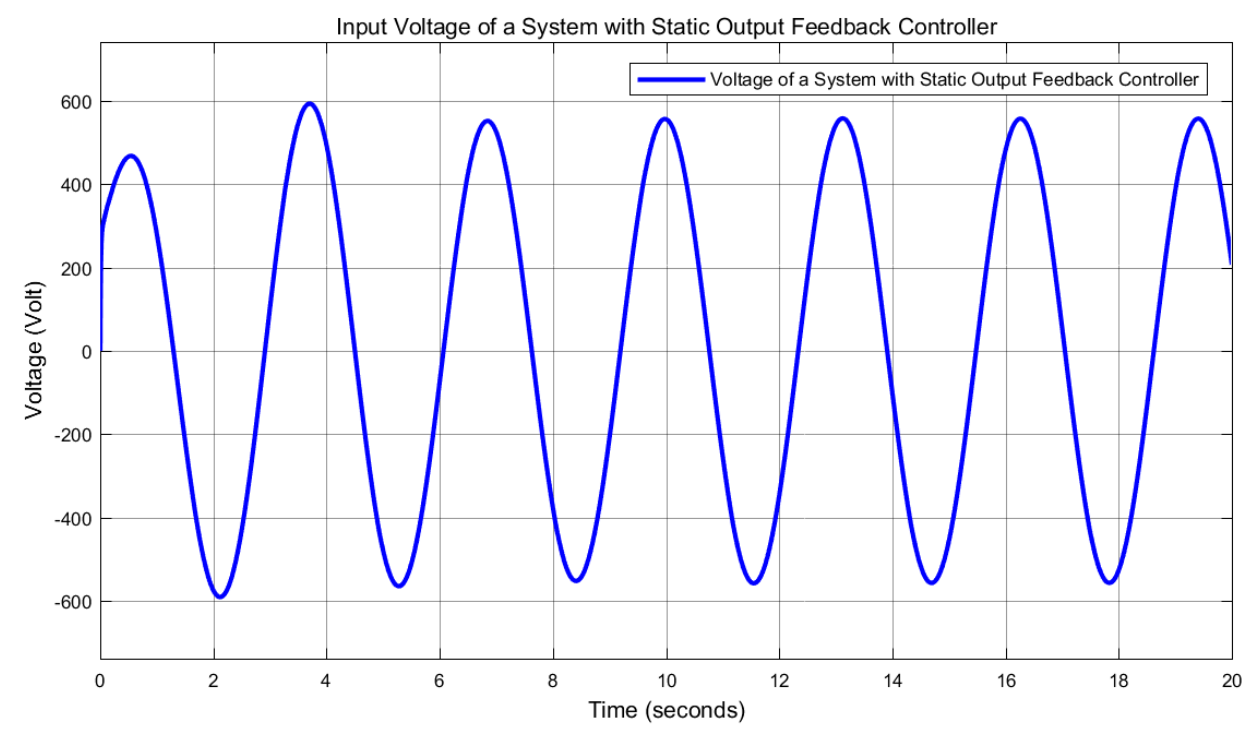

Figure 11 Input voltage to the system with static output feedback controller

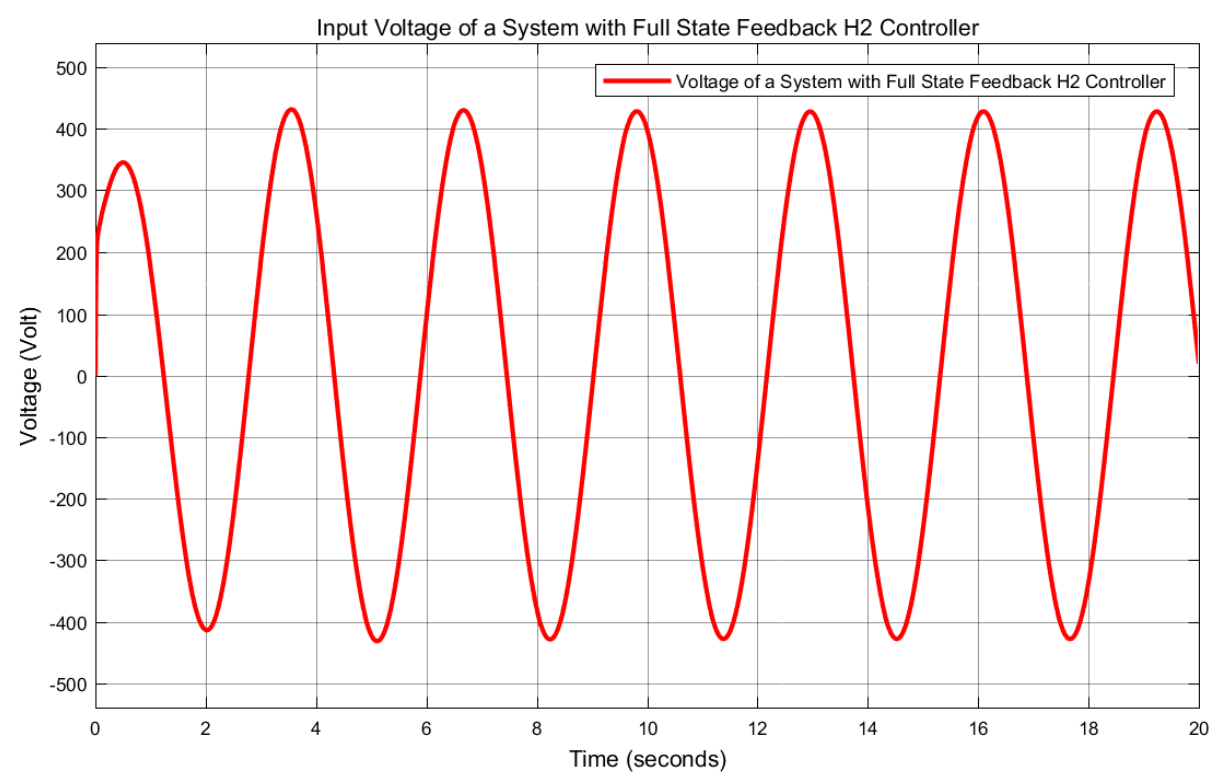

Figure 12 Input voltage to the system with full state feedback controller

The input voltages of the cutting machine system with the proposed controllers shows improvement in reducing the voltage amplitude but the system with full state feedback $\mathrm{H} 2$ controller shows better improvement.

\section{Conclusion}

In this paper, the design and position control of a metal cutting machine have been done using static output feedback and full state feedback $\mathrm{H} 2$ controllers. The open loop response of the system analysis shows that for the system cutting position of $3.4 \mathrm{~m}, 1400$-volt input is needed which is a 
high voltage so the system needs performance improvement. Comparison of the metal cutting machine position using static output feedback and full state feedback $\mathrm{H} 2$ controllers have been done to track a set point position using step and sine wave input signals. Both responses show that the cutting machine system with full state feedback $\mathrm{H} 2$ controller improves the performance of the system by minimizing the percentage overshoot and settling time.

\section{Reference}

[1].Ching Yang Lin et al. "Integration of Cutting Force Control and Chatter Suppression Control into Automatic Cutting Feed Adjustment System Design" Journal of Machining Science and Technology, Vol. 24, Issue 1, 2020.

[2].Eric Dimla et al. "Online Metal Cutting Tool Condition Monitoring: Force and Vibration Analyses" International Journal of Machine Tools and Manufacture, Vol. 40, Issue 5, pp. 739-768, 2020.

[3]. Yuhan Chen et al. "Enhancing the Machining Performance by Cutting Tool Surface Modifications: A Focused Review" Journal of Machining Science and Technology, Vol. 23, Issue 3, 2019.

[4].Jhon O'Hara et al. "Advances in Micro Cutting Tool Design and Fabrication" International journal of Extreme Manufacturing, Vol. 1, Issue 3, 2019.

[5].Zhenyu Han et al. "Cutting Deflection Control of the Blade Based on Real Time Feed Rate Scheduling in Open Modular Architecture CNC System" International Journal of Advanced Manufacturing Technology, Vol. 90, Issue 1, pp. 2567-2579, 2017.

[6]. Mohanad A. et al. "Impacts of Wear and Geometry Response of the Cutting Tool on Machinability of Super Austenitic Stainless Steel" International Journal of Manufacturing Engineering, Vol. 2016, Article ID 7213148, 9 pages, 2016.

[7].Yuan Liu Chen et al. "A Measurement Method of Cutting Tool Position for Relay Fabrication of Micro structured Surface" Measurement Science and Technology, Vol. 25, Issue 6, 2014. 